\title{
PENINGKATAN HASIL BELAJAR PKN MELALUI METODE SIMULASI PADA SISWA KELAS VII SMP NEGERI 2 MARBAU LABUPATEN LABUHANBATU UTARA TAHUN PELAJARAN 2016/2017
}

\author{
IMPROVEMENT OF PKN LEARNING OUTCOMES THROUGH SIMULATION \\ METHODS IN CLASS VII STATE 2 STATE MARBAU NORTH LABUHANBATU \\ LABUPATEN YEAR 2016/2017
}

\author{
JUNITA $\left.{ }^{1^{*}}\right)$, ROHANA ${ }^{2^{*}}$ ) \\ ${ }_{1,2}$ ) FKIP Universitas Labuhan Batu, Jl. SM Raja, No.126 A, Km 3,5, Aek Tapa Rantau Prapat. Indonesia \\ *Email : neetamawar@gmail.com, hanasyarif85@gmail.com
}

\begin{abstract}
Abstrak. Tujuan dari penelitian ini adalah untuk mengetahui peningkatan hasil belajar PKn siswa yang di belajarkan dengan metode ceramah dengan hasil belajar PKn siswa yang dibelajarkan dengan metode Simulasi pada materi perlindungan dan penegakan HAM di kelas VII Negeri 2 Kabupaten Labuhanbatu Utara Tahun Pelajaran 2016/2017. Penelitian ini menggunakan Quasi Eksperimen populasi dalam penelitian ini adalah seluruh siswa kelas VII SMP Negeri 2 Marbau Kabupaten Labuhanbatu Utara berjumlah 240 yang terdiri dari 6 kelas, yakni : kelas VII $1=37$ orang, kelas VII $2=40$ orang, kelas VII $3=40$ orang, kelas VII $4=41$ orang, kelas VII $5=41$ orang. Maka jumlah total populasi $=240$ orang siswa. Sampel yang di tetapkan sebagai kelas terkontrol yaitu kelas VII $2=40$ orang dan kelas yang diberi perlakuan metode simulasi kelas VII $1=37$ orang. Sampel yang di tetapkan sebagai kelas terkontrol yaitu kelas VII $1=37$ orang dan kelas yang diberi perlakuan metode simulasi kelas VII $2=40$ orang. Variabel penelitiannya yaitu : variabel bebasnya : metode simulasi dan variabel terikat : Hasil belajar. Pembelajaran dengan menggunakan metode simulasi efektif dalam meningkatkan prestasi belajar siswa yang ditandai dengan peningkatan ketuntasan belajar siswa. Kesimpulan dari penelitian ini adalah penerapan metode pembelajaran Guided Discovery mempunyai pengaruh positif, yaitu dapat meningkatkan motivasi belajar siswa yang ditunjukkan dengan ratarata jawaban siswa yang menyatakan bahwa siswa tertarik dan berminat dengan metode pembelajaran Guided Discovery sehingga mereka menjadi termotivasi untuk belajar.
\end{abstract}

\section{Keyword: Metode Simulasi, Hasil Belajar}

Abstrak. The purpose of this study was to determine the increase in PKn learning outcomes of students who were taught by the lecture method with PKn learning outcomes of students who were taught with Simulation methods on the material for the protection and enforcement of human rights in class VII Negeri 2, Labuhanbatu Utara Regency, Academic Year 2016/2017. This study used a Quasi Experiment population in this study were all students of class VII SMP Negeri 2 Marbau North Labuhanbatu District totaling 240 consisting of 6 classes, namely: class VII $1=37$ people, class VII $2=40$ 
tfol. 6, No.2 (2019)

Hal:67-74

people, class VII $3=40$ people, class VII $4=41$ people, class VII $5=41$ people. Then the total population $=240$ students. The sample is set as a controlled class that is class VII $2=40$ people and the class treated with a simulation method class VII $1=37$ people. The sample was designated as a controlled class, namely class VII $1=37$ people and the class treated with simulation method class VII $2=40$ people. The research variables are: independent variables: simulation methods and dependent variables: Learning outcomes. Learning by using the simulation method is effective in increasing student achievement which is marked by an increase in student learning completeness. The conclusion of this study is the application of the Guided Discovery learning method has a positive effect, which can increase student motivation shown by the average student answers stating that students are interested and interested in Guided Discovery learning methods so that they become motivated to learn.

Keyword: Simulation Method, Learning Outcomes 


\section{PENDAHULUAN}

Pendidikan pancasila dan kewarganegaraan merupakan wahana untuk mengembangkan dan melestarikan nilai luhur dan moral yang berakar pada budaya bangsa Indonesia yang diharapkan dapat diwujudkan dalam bentuk perilaku dalam kehidupan sehari-hari siswa, baik sebagai individu maupun sebagai anggota masyarakat, warga Negara, dan makhluk hidup ciptaan Tuhan Yang Maha Esa. Perilaku-perilaku yang dimaksud diatas seperti yang tercantum di dalam penjelasan undang-undang tentang sisten pendidikan Nasional, pasal 39 ayat 2, yaitu perilaku yang memancarkan iman dan takwa terhadap Tuhan Yang Maha Esa dalam masyarakat yang terdiri dari berbagai golongan agama, perilaku yang bersifat persatuan bangsa yang beranekaragam kebudayaan dan beranekaragam kepentingan perilaku yang mendukung kerakyatan yang mengutamakan kepentingan perorangan dan golongan sehingga perbedaan pemikiran, pendapat atau kepentingan diatas melalui musyawarah serta perilaku yang mendukung upaya keadilan social bagi seluruh rakyat Indonesia.

Dengan situasi seperti ini guru harus dapat mengambil suatu tindakan guna harus dapat mengambil suatu tindakan guna mensiasati apa yang terjadi di kelas. Guru kelas dapat mengubah strategi agar kemampuan siswa dalam mengeluarkan pendapat semakin meningkat. Salah satu cara yang dapat di tempuh berkaitan dengan inovasi tugas mengajar guru adalah guru hendaknya mempunyai kemampuan dalam mengembangkan metode mengajarnya.

Pemilihan metode mengajarnya ini juga perlu diperhatikan karena tidak semua materi dapat diajarkan dengan hanya satu metode mengajar. Guru hendaknya dapat memilih metode mengajar yang dianggap sesuai dengan materi yang hendak diajarkan. Hal ini dimaksud agar pengajaran khususnya mata pelajaran Pendidikan kewarganegaraan (PKn) dapat berlangsung secara efektif, efesien, dan tidak membosankan.

Berdasarkan observasi awal yang saya lakukan dengan mengadakan wawancara dengan guru PKn kelas VII, maka penelitian ini akan dilaksanakan di kelas VII SMP. Oleh karena itu untuk meningkatkan hasil belajar siswa khusunya pada mata pelajaran PKn.

Berpedoman pada penjelasan diatas maka peneliti tertarik ingin melakukan suatu penelitian sebagai upaya dalam melalukan perbaikan terharap pembelajaran dengan judul "Peningkatan Hasil Belajar PKn Melalui Metode Simulasi Pada Siswa kelas VII SMP Negeri 2 Marbau Kabupaten Labuhanbatu Utara Tahun Pelajaran 2016/2017.

Dalam kegiatan belajar terjadi perubahan perilaku, sebagaimana dikemukakan oleh Dimyanti (2002:18) bahwa belajar merupakan suatu proses internal yang kompleks, yang terlibat dalam proses internal tersebut adalah yang meliputi unsur afektif, dalam mitra afektif berkaitan dengan sikap, nilai-nilai, interes, apresiasi, dan penyesuaian perasaan sosial.

Suparno dalam Sadirman (2004:38) mengemukakan beberapa prinsip dalam 
Hal: $67-74$

belajar yaitu : (1) Belajar berarti mencari makna. Maka diciptakan apa yang mereka lihat, dengar, rasakan dan alami, (2) Konstruksi makna adalah proses yang terus menerus, (3) Belajar bukanlah kegiatan mengumpulkan kegiatan mengumpulkan fakta, tetapi merupakan pengembangan pemikiran dengan membuat pengertian yang baru. Belajar bukanlah hasil perkembangan, tetapi perkembangan itu sendiri, (4) Hasil belajar dipengaruhi oleh pengalaman subjek belajar dengan dunia fisik dan lingkungannya, dan (5) Hasil belajar seseorang tergantung pada apa yang telah diketahui, si subjek belajar, tujuan, motivasi yang mempengaruhi proses interkasi dengan bahan yang sedang dipelajari.

Metode mengajar adalah merupakan salah satu cara yang dipergunakan guru dalam mengadakan hubungan dengan siswa pada saat berlangsungnya pengajaran. Suryosubroto (2002:43).

Metode adalah cara yang digunakan untuk mengimplementasikan rencana yang sudah disusun dalam kegiatan nyata agar tujuan yang telah disusun tercapai secara optimal. Sanjaya (2007:145).

Simulasi berasal dari bahasa Inggris "Simulation" yang artinya pekerjaan tiruan atau meniru. Dalam kegiatan belajar maka metode simulasi merupakan suatu model pembelajaran dimana siswa melakukan suatu peran untuk menggambarkan kejadian yang sebenarnya.

Hal ini sejalan dengan pendapat yang dikemukakan oleh Abu Ahmadi (2005:83), bahwa sebagai metode mengajar simulasi dapat diartikan sebagai suatu kegiatan yang menggambarkan keadaan sebenarnya. Maksudnya ialah siswa (dengan bimbingan guru) melakukan peran dalam simulasi tiruan untuk mencoba menggambarkan kejadian yang sebenarnya. Maka dalam keadaan simulasi, peserta atau pemegang peranan melakukan lingkungan tiruan dari kejadian yang sebenarnya.

Hal senada juga dikemukakan oleh Sanjaya (2007:157) bahwa simulasi berasal dari kata sumulate yang artinya berpura-pura atau berbuat seakan-akan. Sebagai metode mengajar, simulasi dapat diartikan cara penyajian pengalaman belajar dengan menggunakan situasi tiruan untuk memahami tentang konsep, prinsip, atau keterampilan tertentu. Simulasi dapat digunakan sebagai metode mengajar dengan asumsi tidak semua proses pembelajaran dapat dilakukan secara langsung pada objek yang sebenarnya. Belajar bagaimana cara mengoperasikan sebuah mesin yang mempunyai karakteristik khusus misalnya, siswa sebelum menggunakan mesin yang sebenarnya akan lebih bagus melalui simulasi terlebih dahulu. Demikian juga untuk mengembangkan pemahaman dan penghayatan terhadap suatu peristiwa, pengunaan simulasi akan dapat bermanfaat.

Ahmadi (2005:83) menyatakan ada beberapa tujuan dari kegiatan atau pelatihan simulasi yaitu sebagai berikut : 
1) Untuk meningkatkan kegiatan belajar siswa dengan melibatkan siswa dalam mempelajari situasi yang hamper serupa demham kejadian yang sebenarnya.

2) Untuk melatih siswa yang menguasai keterampilan tertentu, baik yang bersifat professional maupun yang sangat penting bagi kehidupan sehari-hari.

3) Untuk pelatihan memecahkan masalah.I

4) Untuk memberikan rangsangan atau kegairahan belajar siswa.

5) Untuk merasakan atau memahami tingkah laku manusia dan situasi-situasi masyarakat disekitarnya.

6) Untuk melatih dan membantu siswa dalam memimpin, bergaul dan memahami hubungan antara manusia, bekerjasama dalam kelompok dengan efektif, menghargai dan memahami perasaan dan pendapat orang lain, dan memupuk daya krearifitas siswa.

Peran guru dalam metode simulasi bagi siswa yaitu : (1) Menjelaskan garis besar berbagai aturan dan kegiatan, (2) Mewasiti, artinya guru harus membentuk kelompok-kelompok dan guru harus mengawasi partisipasi dalam permainan simulasi, (3) Melatih yaitu memberi petunjuk-petunjuk kepada siswa agar mereka dapat bermain dengan baik dan, (4) memimpin diskusi atau membicarakan tanggapan siswa dan bagaimana permainan simulasi itu dinyatakan dengan kehidupan yang sebenarnya.

Kelebihan Metode Simulasi

1. Siswa dapat melakukan interaksi dan komunikasi dalam kelompoknya.

2. Aktivitas siswa cukup tinggi dalam pembelajaran sehingga terlibat langsung dalam pembelajaran.

3. Dapat membiasakan siswa untuk memahami permasalahan sosial atau merupakan implementasi pembelajaran yang berbasis kontekstual.

4. Dapat membina hubungan personal yang positif.

5. Dapat membangkitkan imajinasi.

6. Membina hubungan komunikatif dan bekerjasama dalam kelompok.

\section{METODE PENELITIAN Tempat Penelitian}

Lokasi penelitian merupakan tempat dimana penelitian dilaksanakan. Lokasi penelitian ini sangat penting dalam setiap penelitian karena dari lokasi penelitian inilah peneliti dapat memperoleh data yang dapat diperlukan. Jadi sebelum penelitian dilaksanakan, terlebih dahulu ditetapkan lokasi penelitian. Penelitian ini dilaksanakan dengan mengambil lokasi di SMP Negeri 2 Marbau Kabupaten 
Labuhanbatu Utara.

\section{Waktu Penelitian}

Penelitian ini dilakukan pada bulan Mei sampai dengan Juni tahun 2014. Jenis Penelitian

Berdasarkan sifatnya penelitian ini menggunakan jenis penelitian kuantitatif, Pada penelitian yang dipakai adalah teknika analisis korelasi untuk mengolah data kuantitatif. Untuk menghitung koefesien korelasi pengajaran remedial dengan prestasi belajar siswa digunakan rumus statistic product moment (Arikkunto, 2002:146)

\section{Sumber data \\ Data Primer}

Data Primer yang digunakan dalam penelitian ini berupa melakukan observasi pengumpulan data dengan menggunakan pengamatan dan peninjauan langsung oleh peneliti dan lokasi penelitian untuk melihat secara langsung situasi dan keadaan yang sebenarnya dan masalah yang akan diteliti.

\section{Data Sekunder}

Data Skunder yang digunakan dalam penelitian menggunakan data pendukung untuk memperkuat hasil penelitian berupa referensi buku, jurnal, dan dokumentasi lainya untuk mendukung dalam penelitian.

\section{Analisis Data}

Pada penelitian ini teknik analisa data yang dipakai adala teknik analisa korelasi untuk mengelola data kuantitatif. Untuk menghitung koefsien korelasi pengajaran remedial dengan prestasi belajar sisawa digunakan rumus product moment (Arikunto: 2002: 146).

\section{HASIL PEMBAHASAN}

Dari hasil penelitian uji normalitas dari sekelompok eksperimen di dapat L0 pre test dan post test sebesar 0,1603 dan 0,1511 dan sekelompok control di dapat L0 pre test dan post test sebesar 0,161. Oleh karena itu LO < Lt maka hipotesis nil (Ho) diterima. Dengan demikian dapat disimpulkan bahwa kedua kelompok sampel tersebut dalam sebaran normal.

Dan hasil perhitungan uji homogenitas kelompok eksperimen Fh 0,98 dan kelompok control di dapat Fh sebesar 1,61 dan Lt sebesar 1,86. Oleh karena Fhitung < Ftable, maka hipotesis nol (Ho) diterima pada taraf signifikansi $a=0,05 \mathrm{~m}$, (5\%). Dengan demikian dapat disimpulkan bahwa kedua kelompok sampel tersebut bersifat homogeny.

Dan dari hasil perhitungan diketahui nilai hasil belajar PKn sistem sebelum dan sesudah diberi perlakuan kelompok eksperimen mempunyai skor rata-rata sebesar 20,16 , sedangkan kelompok control mempunyai skor rata-rata sebesar 17,16 . Hal tersebut belum dapat membuktikan adanya perbedaan hasil belajar PKn sistem sebelum dan sesudah pemberian perlakuan pada kelompok eksperimen dan control.

Kemudian perbedaan yang ada, dianalisis dengan menggunakan uji-t dari hasil perhitungan di dapat harga thitung sebesar 1,24. Sedangkan harga ttable sebesar 2,01 . Setelah thitung dibandingkan dengan harga ttable, ternyata harga thitung lebih kecil dari pada harga ttable pada taraf signifikasi $5 \%$. Dengan demikian maka thitung 
$1,24<$ ttable 2,01, sehingga disimpulkan bahwa hipotesis nol (Ho) diterima.

Hal ini dapat disimpulkan bahwa tidak terdapat perbedaan peningkatan hasil belajar PKn yang menggunakan metode simulasi dan metode ceramah.

\section{Kesimpulan}

Kesimpulan merupakan hasil dari pembahasan penelitian yang telah dilakukan dan dari hasil analisa data yang telah dilakukan oleh peneliti, maka diperoeleh kesimpulan sebagai berikut:

1) Berdasarkan hasil penelitian dengan hasil analisis data observasi langsung dan tes hasil belajar maka dapat disimpulkan bahwa penggunaan metode simulasi pada konsep pembelajaran hak asasi manusia lebih tinggi dari pada metode ceramah. Tetapi perbedaan itu tidak signifikan.

2) Minimnya pengetahuan dan wawasan siswa mengenai metode simulasi sehingga siswa kurang memahami langkah-langkah permainan simulasi.

3) Guru harus membuat rencana yang matang di sertai waktu yang baik agar setiap kegiatan dalam metode simulasi dapat berjalan dengan harapan.

4) Guru harus berusaha memahami dengan benar tentang makna dan langkahlangkah metode permainan simulasi serta pandai dan kreatif dalam memberikan penjelasan dan pengarahan yang jelas kepada siswa.

5) Guru harus bisa memberikan kreativitas dalam membuat permainan yang dimiliki nilai edukatif dan mudah dilakukan sehingga siswa dapat terlihat semuanya.

\section{Ucapan Terima Kasih}

Penulis mengucapkan banyak terima kasih kepada Kepala Sekolah SMP Negeri 2 Marbau Labupaten Labuhanbatu Utara, guru mata pelajaran PKn atas bantuan kesedian dalam penelitian ini, dan kepada pihak SMP Negeri 2 Marbau Labupaten Labuhanbatu Utara yang telah memberikan data dan informasi dalam penelitian ini.

\section{DAFTAR PUSTAKA}

Abu Ahmadi. 2005. Strategi Belajar Mengajar. Pustaka Setia. Bandung

Anita. 2007. Pengantar Statistik Pendidikan. Jakarta. Raja Grafindo Persada

Dimyanti Mudjiono. 2002. Belajar dan Pembelajaran. Jakarta. Rineka Cipta

Muhibbin Syah. 1996. Psikologi Pendidikan. Bandung. Remaja Rosda Karya

Nana Sudjana. 2005. Dasar-dasar Proses Belajar Mengajar. Bandung. Sinar Baru Algensindo

Roestiyah. 2001. Strategi Belajar Mengajar. Rineka Cipta. Jakarta

Slameto. 2003. Belajar dan Faktor-faktor yang Mempengaruhinya. Jakarta. Rineka cipta

Sanjaya. 2007. Interaksi dan Motivasi Belajar Mengajar. Jakarta. Rajawali Pers 
tfol. 6, No.2 (2019)

$\mathrm{Hal}: 67-74$

Suryosubroto. B. 2002. Proses Belajar Mengajar Di Sekolah. Jakarta. Rineka Cipta.

[10]. Muntoha, Pendidikan Dalam Perspektif Hukum (Antara Harapan dan Realita), Jurnal Madaniyah, Vol. 1 Edisi X Januari. ISSN 2086-3462, Halaman: 94:2016.

[11]. Ihksan, 2017. Kecendrungan Global Dalam Proses Pembelajaran Pendidikan Pancasila dan Kewarganegaraan dan Kewarganegaraan di Sekolah, Jurnal Pancasila dan Kewarganegaraan, Vol. 2, No. 2, Juli, ISSN 25277057 (Online), ISSN 2545-2683 (Printed). Halaman: 54:2017.

[12]. Rinoyo Gusdiwo, dkk, Hubungan Antara Pengetahuan Hukum Dengan Tingkat Kepatuhan Terhadap Tata Tertib Sekolah Pda Siswa Kelas X SMA Negeri 4 Yogyakarta, Fakultas IImu Sosial, Universitas Negeri Yogyakarta, Halaman: 12:2016.

[13]. Yuniastuti, Eksistensi, Moral dalam Pendidikan, Jurnal Pendidikan Pancasila dan Kewarganegaraan, Th 23, Nomor 2, Agustus, Halaman:40:2010. 